\title{
Management of Neuropathic Pain-Current Insights and Future Perspectives
}

\author{
Howard S Smith, MDํㅗ Sukriye Damla Kara² and Charles E Argoff, MD³ \\ 1. Professor and Academic Director of Pain Management, Department of Anesthesiology, Albany Medical College, New York, US; \\ 2. Undergraduate Student, University of Rochester, New York, US; 3. Professor of Neurology and Director, \\ Comprehensive Pain Center, Department of Neurology, Albany Medical College, New York, US
}

\begin{abstract}
The management of neuropathic pain remains very challenging and very much an art. Despite the publication of multiple consensus guidelines on the management of neuropathic pain, a significant subpopulation of patients with neuropathic pain are not afforded adequate relief, employing various treatment algorithms with conventional pharmacologic therapeutic strategies. First-line agents for the treatment of neuropathic pain include: tricyclic antidepressants, selective serotonin/norepinephrine re-uptake inhibitors, calcium channel $\alpha 2-\delta$ ligands and, in certain cases of focal neuropathic pain, a lidocaine patch. Novel analgesics under development may include: purinergic receptor modulators, cannabinoid receptor modulators, neurokinin-1 (NK-1) receptor modulators, glial modulators, rostral ventral medulla 'on-cell' modulators, chemokine receptor modulators, toll-like receptor modulators, modulators of tetrahydrobiopterin synthesis, and/or chemically re-engineered conotoxins. It is hoped that future agents and/or combinations of agents may be helpful to this refractory subpopulation.
\end{abstract}

\section{Keywords}

Neuropathic, pain, treatment, calcium channel $\alpha 2-\delta$ ligand, antidepressants

Disclosure: Howard S Smith, MD, and Sukriye Damla Kara have no conflicts of interest to declare. Charles E Argoff, MD, has received an honorarium and/or grant from Endo, Pfizer, Lilly, Forest, and Neurogesx for his role as advisor, investigator and member of their speaker bureau. He has also received an honorarium from King, Sanofi-Aventis, Boehringer Ingelheim, Nuvo Research, and Jazz for his role as advisor and from Picara for participation on their speaker bureau. Received: February 1, 2012 Accepted: March 19, 2012 Citation: US Neurology, 2012;8(1):57-61 DOI: 10.17925/USN.2012.08.01.57 Correspondence: Howard S Smith, MD, Professor and Academic Director of Pain Management, Department of Anesthesiology, Albany Medical College, 47 New Scotland Avenue, MC-131, Albany, NY 12208, US. E: smithh@mail.amc.edu

\section{Neuropathic Pain Definition, Diagnosis and Clinical Presentation}

Neuropathic pain (NP) originates as a result of a lesion or disease (e.g., diabetes, herpes zoster, HIV infection, chemotherapy or surgery) pertaining to the somatosensory system. ${ }^{1} \mathrm{NP}$ can be classified as peripheral or central depending on where the lesion/disease is located. ${ }^{2}$ The clinical presentation of NP includes both positive and negative sensory phenomena: e.g., pain and lack of sensation. The presence of NP can be categorized in three groups depending on the certainty of its existence: the 'definite' and 'probable' levels indicate that the presence of NP is established, and the 'possible' level does not confirm the existence of this condition. ${ }^{2}$ These levels are assigned by using the NP grading system, which consists of four criteria:

- pain with a distinct neuroanatomically plausible distribution;

- a history suggestive of a relevant lesion or disease affecting the peripheral or central somatosensory system;

- demonstration of the distinct neuroanatomically plausible distribution by at least one confirmatory test; and

- demonstration of the relevant lesion or disease by at least one confirmatory test.
If all of the four criteria stated above are met, the diagnosis of definite NP is made. Probable NP is present if the first, second and either the third or fourth criteria are met. The diagnosis of possible NP requires the first two criteria without the third or fourth. If the patient fails to exhibit the criteria for these three levels, the NP is considered as absent. ${ }^{2}$ Commonly used recent screening tools to identify NP include Leeds assessment of neuropathic symptoms and signs, Douleur neuropathique 4 questions, Neuropathic questionnaire, painDETECT, and ID Pain. Bennett et al. conducted research in 2007 investigating these five screening tools and noted that three symptomatic items ('prickling, tingling, pins and needles', 'electric shocks or shooting', and 'hot or burning') were found in all tools. Also 'numbness' and 'pain evoked by light touching' were present in $80 \%$ of the tools investigated in Bennett et al.'s research. ${ }^{3}$ Quantitative sensory testing (QST) is one of the tools useful in evaluating sensation, focusing on the definition of the stimulus properties, the quantity of sensory intensity and the quality of sensation. QST, skin biopsies, imaging electrodiagnostic studies, pertinent ancillary data and the symptoms exhibited by the patient should be studied while treating the NP. The clinician should consider a 'rational polypharmacotherapy' for the case if a single agent is not enough to relieve the NP. ${ }^{4}$ The illness or injury preceding NP may present itself with both medical and psychiatric comorbidities, disturbing the diagnosis and assessment of NP. Backonja and Argoff ${ }^{5}$ suggested an outline of 
multidimensional pain assessment (MDPA) to establish the complete clinical diagnosis of individual patients. Multiple dimensions of NP include medical etiology, pain management, psychiatric comorbidities, and quality of life/ability to function. Ranking each dimension as 'none', 'mild', 'moderate', or 'severe' helps assess multidimensional pain.

\section{Treatment of Neuropathic Pain}

The treatment of NP is difficult because less than half of patients receive satisfactory pain relief (>30 \% reduction) while side effects are common. Although being treated with multiple medications, studies have shown that NP patients continue to have pain of moderate severity. ${ }^{6} \mathrm{O}^{\prime} \mathrm{Connor}$ states that this inefficacy may result in part from inappropriate medication prescription or use of insufficient dosage in treating these patients. The Neuropathic Pain Special Interest Group (NeuPSIG) outlined three lines of medications to treat NP. ${ }^{7}$ Combinations of medications appear to provide greater pain relief compared with monotherapy, although there is not a great deal of evidence surrounding combination therapy. There are also non-pharmacologic approaches to the treatment of NP which include: physical medicine approaches, behavioral approaches, interventional approaches, surgical approaches, and neuromodulation approaches.

\section{Medication Management of Neuropathic Pain- Current Recommendations}

The International Association for the Study of Pain (IASP) NeuPSIG, an international consensus process that included a diverse group of pain experts, was convened to develop evidence-based guidelines for the pharmacologic treatment of NP. These guidelines were endorsed by the American Pain Society, the Canadian Pain Society (CPS), the Finnish Pain Society, the Latin American Federation of IASP Chapters, and the Mexican Pain Society.? Additional consensus guidelines for the pharmacologic treatment of NP were created simultaneously by the European Federation of Neurological Societies (EFNS) ${ }^{8}$ and the CPS. ${ }^{9}$ The first-line agents for NP recommended by the IASP NeuPSIG included: tricyclic antidepressants (TCAS), calcium channel $\alpha 2-\delta$ ligands, selective serotonin/norepinephrine re-uptake inhibitors (SNRIS) and topical lidocaine (for localized peripheral NP). ${ }^{7}$ Opioids and tramadol were recommended as second-line agents except in selected circumstances, such as the treatment of acute NP, episodic exacerbations of severe NP and neuropathic cancer pain and during the titration of a first-line agent in patients with severe pain. ${ }^{7}$ The CPS guidelines recommended TCAS and calcium channel $\alpha 2-\delta$ ligands as first-line medications. ${ }^{9}$ SNRIs and topical lidocaine (for localized peripheral NP) were recommended as second-line medications and opioid analgesics and tramadol were recommended as third-line analgesic agents for the treatment of NP. ${ }^{9}$ In 2010, the EFNS updated its guidelines..$^{10}$ Recommendations for first-line agents for diabetic NP included: duloxetine, gabapentin, pregabalin, TCAs, and venlafaxine extended-release. Opioids and tramadol were recommended as second-line agents for diabetic NP. Recommendations for first-line agents for postherpetic neuralgia (PHN) were gabapentin, pregabalin, TCAs, and lidocaine plasters with opioids and topical capsaicin (topical 0.075 and $8 \%$ capsaicin patch [Qutenza ${ }^{\circledR}$ ]). Recommendations for first-line agents for central pain were gabapentin, pregabalin, and TCAs. ${ }^{10}$

\section{Antidepressants}

Antidepressants are a heterogeneous group of drugs which have all demonstrated beneficial activity for patients with major depressive disorder. Antidepressants can be classified in multiple ways; however, a simplistic yet clinically useful categorization divides them into TCAs, SNRIS, selective serotonin re-uptake inhibitors (SSRIS) and selective norepinephrine (noradrenalin) re-uptake inhibitors (NRIS or NARIS).

\section{Tricyclic Antidepressants}

The TCAs can be divided into amines and their demethylated secondary amine derivatives. The tertiary amine TCAs include the following:

- amitriptyline (Elavil $\left.{ }^{\circledR}\right)$;

- imipramine (Tofranil $\left.{ }^{\circledR}\right)$;

- trimipramine (Surmontil $\left.{ }^{\circledR}\right)$;

- clomipramine (Anafranil$\left.{ }^{\circledR}\right)$; and

- doxepin (Sinequan ${ }^{\circledR}$ ).

The secondary amine TCAs include the following:

- nortriptyline (Pamelor $\left.{ }^{\circledR}\right)$;

- desipramine (Norpramin $\left.{ }^{\circledR}\right)$;

- $\quad$ protriptyline (Vivactil $\left.{ }^{\circledR}\right)$; and

- amoxapine (Asendin ${ }^{\circledR}$ ).

In 1987, Max et al. demonstrated that TCAs possess analgesic effects independent of their effects on moods. ${ }^{11}$ Furthermore, as a generalization it was found later on that the analgesic effects from TCAs tend to occur more rapidly (at roughly a week or less after initiating TCA therapy) and at lower doses than those used for antidepressant effects. TCAs have been extensively used in the treatment of different types of NP and multiple randomized controlled trials (RCTs) have demonstrated their efficacy for various types of NP, excluding pain in HIV and chemotherapy-induced peripheral neuropathies. ${ }^{12-14}$ The mechanism of action of TCAs includes both norepinephrine and serotonin re-uptake inhibition. Certain TCAs, such as amitriptyline and doxepin, have demonstrated sodium channel blocking ability as well. Among the most commonly used TCAs are nortriptyline and desipramine, not only because of their analgesic properties but because of their fewer side effects in comparison with other TCAs (tertiary amines) such as amitriptyline. ${ }^{15,16}$ TCAs may exhibit a wide range of adverse effects and differ significantly as regards which TCAs have which effects. Adverse effects include: anticholinergic effects (desipramine has the least anticholinergic effects), antihistaminergic effects (doxepin has the most potent antihistaminergic effects), $\alpha-1$ adrenergic receptor blockade (e.g., orthostatic hypotension), and cardiac effects (increasing intraventricular conduction, prolonged QT interval, prolonged through the atrioventricular node). Other side effects of TCAs include orthostatic hypotension as well as those related to their anticholinergic activity including urinary retention, dry mouth, and constipation. Cardiac toxicity has been described as a possible side effect of TCAs; sinus and ventricular arrhythmias were noted in patients with a history of coronary artery disease (CAD) and depression who were on nortriptyline. ${ }^{17} \mathrm{~A}$ large review study has shown some cardiac complications, including myocardial infarction, with doses more than $100 \mathrm{mg} /$ day, but did not demonstrate adverse cardiac outcomes in patients who were on a regimen of less than $100 \mathrm{mg} /$ day. ${ }^{18}$ One of the advantages of TCAs is that they are taken once daily and are not expensive. When committing a patient with NP to treatment with TCAs, the lowest effective dose should be used. In patients with a history of arrhythmias and CAD, TCAs should be avoided 
and obtaining an electrocardiogram prior to starting treatment in patients over 40 years old is recommended. ${ }^{19}$

Multiple reviews have evaluated that placebo-controlled RCTs found TCAs to be efficacious for several different types of NP.7,12,14,20-22 In older persons, TCAs, especially tertiary amines such as amitriptyline, may exhibit too many adverse effects to be used. In fact, over time, amitriptyline consistently appears on the Beers list ${ }^{23,24}$ of medications that are suggested to be inappropriate when treating older persons. Thus, in frail older patients, duloxetine may be a reasonable choice and clinicians may trial an initial dose of half a tablet for a week to assess how well they tolerate this medication. Duloxetine is also available in $20 \mathrm{mg}$ tablets for old and frail patients.

Although the role of SSRIS in providing effective analgesia is uncertain, it appears limited at best. ${ }^{22}$

\section{Selective Serotonin/Norepinephrine Re-uptake Inhibitors}

Duloxetine and venlafaxine are antidepressants with both serotonergic and noradrenergic re-uptake inhibiting properties (SNRIS). The former has been extensively studied and used in the treatment of diabetic neuropathy and has been demonstrated to be efficacious over placebo in multiple RCTs that showed doses of 60 and $120 \mathrm{mg} /$ day to be both safe and effective. ${ }^{25-27}$ The side effect profile of duloxetine seems to be more favorable than TCAs, especially with respect to anticholinergic and cardiac side effects. Nausea has been reported as one of the common side effects and is reduced by lowering the dose. ${ }^{28}$ For many patients, nausea is self-limited and resolves within the first several weeks of usage. Duloxetine has been extensively studied in patients with diabetic peripheral neuropathy, fibromyalgia, musculoskeletal back pain, and osteoarthritis, and is Food and Drug Administration (FDA)-approved for all four indications. Venlafaxine has been effective in the treatment of diabetic painful neuropathy (DPN) and other polyneuropathies, except PHN. ${ }^{7}$ A small subset of patients demonstrated cardiac conduction abnormalities; thus precautions should be taken in patients with a history of cardiac pathologies. Venlafaxine should be tapered rather than abruptly discontinued because of a withdrawal syndrome that has been reported. ${ }^{29}$ At doses less than $150 \mathrm{mg} /$ day, venlafaxine behaves more like a serotonergic-specific re-uptake inhibitor or SSRI; at doses above $150 \mathrm{mg}$, it behaves more like an SNRI agent and pain relief is more likely to occur with doses of $150 \mathrm{mg}$ /day or greater. Venlafaxine is not FDA-approved for any pain indication.

\section{Calcium Channel Alpha-2 Delta Ligands}

Gabapentin and pregabalin are calcium channel $\alpha 2-\delta$ ligands. The mechanism of action of each of these is through their ability, in an excited neuron, to reduce calcium influx into the neuron with subsequent reduction of neurotransmitter release such as substance $P$, glutamate and norepinephrine. ${ }^{30-36}$ Although calcium channel ligands can lead to dose-dependent somnolence and dizziness, as well as weight gain and peripheral edema, they have few drug-drug interactions. Their dose must be lowered in patients with renal insufficiency.? Another advantage of pregabalin is that it has some anxiolytic effects, which is frequently helpful with concurrent anxiety seen in patients with NP. ${ }^{37}$ Gabapentin is FDA-approved for PHN. Pregabalin is FDA-approved for PHN as well as DPN and fibromyalgia.
Gabapentin exhibits non-linear pharmacokinetics. That is, as doses are increased, less of the drug is absorbed and therefore much of it is excreted in the urine rather than being clinically effective. It should be introduced to a patient in a low-dose fashion and increased until analgesia has been achieved or side effects are experienced. The maximum recommended dosage of gabapentin is $3,600 \mathrm{mg} /$ day for DPN and $1,800 \mathrm{mg} /$ day for PHN and its effect can be seen as soon as two weeks, although an adequate therapeutic trial can take up to several months. ${ }^{1}$ Gabapentin is now available in extended-release formulations. Although pregabalin and gabapentin have identical mechanisms of action, pregabalin has improved pharmacokinetics and linear bioavailability, both of which are significant advantages. Its onset of analgesia is faster than gabapentin, secondary to its shorter titration period. The current recommendations are titration up to $300 \mathrm{mg}$ /day divided into three doses for DPN and up to $600 \mathrm{mg} /$ day divided into three doses for PHN. ${ }^{1}$ For maintenance treatment it is generally dosed twice a day (bid). However, some elderly patients or those patients more sensitive to medication may prefer taking a lower dose three times a day (tid). The doses for both gabapentin and pregabalin should be reduced in patients with chronic kidney disease.

\section{Topical Lidocaine}

The lidocaine patch $5 \%$ is FDA-approved for the treatment of PHN and may be used as a part of multimodal therapy. Several RCTs have established its efficacy over placebo. The mechanism of action is a result of sodium channel blocking of hyperactive sodium ions in damaged peripheral nerves and interference with ectopic impulses ascending to the dorsal horn. This interferes with peripheral and central sensitization and decreases the likelihood of maladaptive neuroplasticity. In addition, the patch itself is a buffer which decreases mechanical allodynia. ${ }^{38,39}$ The most common side effect of the patch is mild skin irritation. The patch should not be used in patients sensitive to lidocaine or type 1 anti-arrhythmics such as tocainide or mexiletine. It should not be used in patients with hepatic insufficiency since lidocaine is metabolized by the liver. Lidocaine crosses the placental barrier and therefore should not be used in pregnancy or by nursing mothers. The $5 \%$ lidocaine patch and $5 \%$ lidocaine-medicated plaster are safe and appear to be effective and well-tolerated by patients with PHN and allodynia. ${ }^{13,40-46}$ Patients with a small focal area of well-localized NP may benefit from topical lidocaine the most. ${ }^{47}$ Since the drug is not absorbed systemically, there are no systemic adverse effects. Mild local reactions are the most common side effects.

\section{Opioids}

Opioids and tramadol may provide analgesia in multiple NP conditions and multiple RCTs have supported their use. ${ }^{1,7}$ Because of their side effects, which occur more frequently than with the first-line medications and the risk of misuse, opioids are not recommended as a substitute for the first-line medications. ${ }^{48}$ They should be reserved for patients who have failed the first-line regimen, for pain relief during the titration of the first-line medication, for treatment of episodic severe NP and for neuropathic cancer pain. The most commonly reported side effects of opioids are constipation, nausea, vomiting, and sedation. It is recommended to start patients on a bowel regimen to prevent the gastrointestinal symptoms. Moreover, chronic use of opioids may be associated with immunologic changes, endocrine changes 
(e.g., hypogonadism) and the possible development of hyperalgesia. Opioids are not FDA-approved for specific NP conditions. Eisenberg et al. performed a systematic review and meta-analysis and found 22 articles that met inclusion criteria (14 were short-term and eight were intermediate-term). ${ }^{49}$ Short-term studies provided equivocal evidence of opioid efficacy for providing analgesia in NP, but all eight intermediate-term studies demonstrated significant efficacy of opioids over placebo for reducing NP. ${ }^{49}$

\section{Tramadol}

Tramadol is a racemate, with the $(+)$ enantiomer having weak opioid properties and binding to the $\mu$ opioid receptor which accounts for about $30 \%$ of its analgesic activity. The (+) enantiomer also inhibits the re-uptake of serotonin and the (-) enantiomer inhibits the re-uptake of norepinephrine. Tramadol is available in short- and extended-release preparations and the recommended starting dose for the immediate-release tramadol is $50 \mathrm{mg}$ every 6-8 hours. Because of the risk of seizures at higher doses, there is a maximum recommended dose of $400 \mathrm{mg} /$ day. This regimen should be adjusted for patients with kidney or liver pathology. ${ }^{1}$ Tramadol is not FDA-approved for any NP indications.

\section{N-Methyl D-Aspartate Receptor Antagonists}

Inconsistent outcomes for the use of memantine and dextromethorphan have been observed; however, they have been occasionally tried with patients who failed other therapies. ${ }^{7.12}$ Dextromethorphan is effective in a dose-related fashion in selected patients with DPN but not in PHN. ${ }^{50}$

\section{Alpha-2 Adrenoceptor Agonists}

There are three $\alpha-2$ adrenoceptor agonists FDA-approved for use (not analgesic use) in the US. The agents all have antinociceptive properties and may be especially useful when used in conjunction with muscular spasticity/spasms or concomitantly with opioids. Clonidine is primarily used as an antihypertensive agent. It is available in various formulations for multiple routes of administration including oral, sublingual, transdermal, intravenous and epidural. Tizanidine is primarily used as a muscle relaxant/antispasticity agent in an oral tablet form.

\section{Topical Capsaicin}

A high-potency (8\%) capsaicin patch (Qutenza) is FDA-approved for the treatment of PHN pain. It is thought to diminish pain sensation by reducing transient receptor potential vanilloid-1 (TRPV1) expression and decreasing the density of epidermal nerve fibers in the application area. A single 60-minute application may provide up to 12 weeks of analgesia. Derry et al. performed a Cochrane Review in 2009 which included six studies (389 participants) comparing $0.075 \%$ capsaicin cream with placebo cream and two studies comparing $8 \%$ capsaicin patch with placebo patch. ${ }^{51}$ They concluded that capsaicin, either as repeated application of a low-dose (0.075 \%) cream or a single application of an $8 \%$ patch may provide a clinically significant degree of pain relief to some patients with NP. ${ }^{51}$

\section{Combination Therapy}

The use of 'rational polypharmacy' in pain management has not been particularly well studied. Gilron et al. have shown that the combination of gabapentin and morphine achieved better analgesia at lower doses of each drug than either as a single agent for $\mathrm{NP}^{48}$ and that the combination of gabapentin and nortriptyline seems more efficacious than either drug administered as monotherapy for NP. ${ }^{52}$

\section{Potential Future Agents}

Conventional available agents for the treatment of NP remain suboptimal for providing adequate analgesia for all patients with NP. Novel analgesic agents are needed in efforts to improve pharmacologic approaches to combating NP. Potential therapeutic options in the future may include: purinergic receptor modulators, cannabinoid receptor modulators, neurokinin-1 (NK-1) receptor modulators, glial modulators, rostral ventral medulla on-cell modulators (e.g., improgan), chemokine receptor modulators, toll-like receptor modulators, modulators of tetrahydrobiopterin synthesis, and/or chemically re-engineered conotoxins.

\section{Summary}

NP is an extremely complex and challenging problem. Despite the availability and employment of multiple treatment guidelines/algorithms, a significant subpopulation of patients with NP still do not achieve adequate analgesia. At least from the standpoint of pharmacologic approaches to the treatment of NP, this is probably due in part to available agents not significantly affecting important potential therapeutic targets. It is hoped that the development of novel therapeutic agents may expand the achievement of satisfactory analgesia to a larger population of patients currently suffering with NP.
1. O'Connor AB, Dworkin RH, Treatment of neuropathic pain: an overview of recent guidelines, Am $\lrcorner$ Med, 2009;122(10 Suppl.):S22-32.

2. Treede RD, Jensen TS, Campbell JN, et al., Neuropathic pain: redefinition and a grading system for clinical and research purposes, Neurology, 2008;70:1630-5.

3. Bennett Ml, Attal N, Backonja MM, et al., Using screening tools to identify neuropathic pain, Pain, 2007;127:199-203.

4. Smith $\mathrm{HS}$, Sang $\mathrm{CN}$, The evolving nature of neuropathic pain: individualizing treatment, Eur J Pain, 2002;6:13-8

5. Backonja MM, Argoff CE, Neuropathic pain: definition and implications for research and therapy, J Neuropathic Pain Symptom Palliat, 2005:1:11-7.

6. O'Connor AB, Neuropathic pain: quality-of-life impact, costs and cost effectiveness of therapy, Pharmacoeconomics, 2009;27:95-112

7. Dworkin RH, O'Connor AB, Backonja M, et al., Pharmacologic management of neuropathic pain: evidence-based recommendations, Pain, 2007;132:237-51.

8. Attal N, Cruccu G, Haanpää M, et al., EFNS guidelines on pharmacological treatment of neuropathic pain, Eur I Neurol, 2006;13:1153-69.

9. Moulin DE, Clark AJ, Gilron I, et al., for the Canadian Pain
Society, Pharmacological management of chronic neuropathic pain- consensus statement and guidelines from the Canadian Pain Society, Pain Res Manag, 2007;12:13-21.

10. Attal N, Cruccu G, Baron R, et al., EFNS guidelines on the pharmacological treatment of neuropathic pain: 2010 revision, Eur J Neurol, 2010:17:1113-e88.

11. Max MB, Culnane M, Schafer SC, et al., Amitriptyline relieves diabetic neuropathy pain in patients with normal or depressed mood, Neurology, 1987;37:589-96.

12. Finnerup NB, Otto M, MCQuay HJ, et al., Algorithm fo neuropathic pain treatment: an evidence based proposal, Pain, 2005;118:289-305.

13. Hempenstall K, Nurmikko TJ, Johnson RW, et al., Analgesic therapy in postherpetic neuralgia: a quantitative systematic review, PLOS Med, 2005:2:628-44.

14. Sindrup SH, Otto M, Finnerup NB, Jensen TS, Antidepressants in the treatment of neuropathic pain, Basic Clin Pharmacol Toxicol, 2005;96:399-409

15. Max MB, Lynch SA, Muir J, et al., Effects of desipramine, amitriptyline, and fluoxetine on pain in diabetic neuropathy, N Engl । Med, 1992:326:1250-6.

16. Rowbotham MC, Reisner LA, Davies PS, Fields HL, Treatment response in antidepressant-naïve postherpetic neuralgia patients: double-blind, randomized trial, I Pain, 2005:6:741-6.

17. Roose SP, Laghrissi-Thode F, Kennedy JS, et al., Comparison of paroxetine and nortriptyline in depressed patients with ischemic heart disease, JAMA, 1998;279:287-91.

18. Ray WA, Meredith S, Thapa PB, et al., Cyclic antidepressants and the risk of sudden cardiac death, Clin Pharmacol Ther, 2004;75:234-41.

19. Dworkin RH, Backonja M, Argoff $\mathrm{CR}$, et al., Advances in neuropathic pain: diagnosis, mechanisms, and treatment recommendations, Arch Neurol, 2003;60:1524-34.

20. Finnerup NB, Otto $M$, Jensen TS, Sindrup SH, An evidence-based algorithm for the treatment of neuropathic pain, MedGenMed, 2007:9:36-46.

21. Finnerup NB, Sindrup SH, Jensen TS, The evidence for pharmacological treatment of neuropathic pain, Pain, 2010;150(3):573-81.

22. Saarto T, Wiffen PJ, Antidepressants for neuropathic pain, Cochrane Database Syst Rev, 2007;(4):CD005454.

23. Beers MH, Ouslander JG, Rollingher I, et al., UCLA Division of Geriatric Medicine, Explicit criteria for determining inappropriate medication use in nursing home residents, Arch Intern Med, 1991;151:1825-32.

24. Beers MH, Explicit criteria for determining potentially 
inappropriate medication use by the elderly: an update, Arch Intern Med, 1997;157:1531-6.

25. Goldstein DJ, Lu Y, Detke MJ, et al., Duloxetine vs. placebo in patients with painful diabetic neuropathy, Pain, 2005;116:109-18

26. Raskin J, Pritchett $\mathrm{YL}$, Wang F, et al., A double-blind, randomized multicenter trial comparing duloxetine with placebo in the management of diabetic peripheral neuropathic pain, Pain Med, 2005;6:346-56.

27. Wernicke JF, Pritchett YL, D'Souza DN, et al., A randomized controlled trial of duloxetine in diabetic peripheral neuropathic pain, Neurology, 2006;67:1411-20.

28. Smith HS, Bracken D, Smith JM, Duloxetine: A review of its safety and efficacy in the management of fibromyalgia syndrome, J Cent Nerv Syst Dis, 2010;2:57-72.

29. Fava M, Mulroy R, Alpert J, et al., Emergence of adverse events following discontinuation of treatment with extended-release venlafaxine, Am J Psychiatry, 1997;154:1760-2.

30. Backonja M, Beydoun A, Edwards KR, Gabapentin for symptomatic treatment of painful neuropathy in the patients with diabetes mellitus: a randomized trial, JAMA, 1998;280:1831-6.

31. Bone M, Critchley P, Buggy DJ, Gabapentin in postamputation phantom limb pain: a randomized, double-blind, placebo-controlled, cross-over study, Reg Anesth Pain Med, 2002;27:481-6.

32. Caraceni A, Zecca E, Bonezzi C, et al., Gabapentin for neuropathic cancer pain: a randomized controlled trial from the gabapentin cancer pain study group, I Clin Oncol, 2004;22:2909-17.

33. Pandey CK, Bose N, Garg G, et al., Gabapentin for treatment of pain in Guillain-Barre syndrome: a double-blinded, placebo-controlled, crossover study, Anesth Analg, 2002:95:1719-23.

34. Rice ASC, Maton S, Postherpetic Neuralgia Study Group,
Gabapentin in postherpetic neuralgia: a randomized double-blind, placebo controlled study, Pain, 2001; $94: 215-24$.

35. Rowbotham MC, Harden N, Stacey B, et al., Gabapentin for the treatment of postherpetic neuralgia: a randomized controlled trial, JAMA, 1998;280:1837-42.

36. Serpell MG, Gabapentin in neuropathic pain syndromes: a randomized, double-blind, placebo-controlled trial, Pain , 2002;99:557-66.

37. Montgomery SA, Tobias K, Zornberg GL, et al., Efficacy and safety of pregabalin in the treatment of generalized anxiety disorder: a 6-week, multicenter, randomized, double-blind, placebo-controlled comparison of pregabalin and venlafaxine, J Clin Psychiatry, 2006;67:771-82.

38. Galer BS, Rowbotham MC, Perander J, Friedman E, Topica lidocaine patch relieves postherpetic neuralgia more effectively than a vehicle topical patch: results of an enriched enrollment study, Pain, 1999;80:533-8.

39. Rowbotham MC, Davies PS, Verkempinck C, Galer BS, Lidocaine patch: double-blind controlled study of a new treatment method for post-herpetic neuralgia, Pain, 1996;65:39-44.

40. Khaliq W, Alam S, Puri N, Topical lidocaine for the treatment of postherpetic neuralgia, Cochrane Database Syst Rev, 2007;(2):CD004846.

41. Binder A, Bruxelle J, Rogers $P$, et al., Topical $5 \%$ lidocaine (lignocaine) medicated plaster treatment for post-herpetic neuralgia: results of a double-blind, placebo-controlled, multinational efficacy and safety trial, Clin Drug Investig, 2009;29:393-408

42. Baron R, Mayoral V, Leijon G, et al., $5 \%$ lidocaine medicated plaster versus pregabalin in post-herpetic neuralgia and diabetic polyneuropathy: an open-label, non-inferiority two-stage RCT study, Curr Med Res Opin, 2009:25:1663-76.

43. Wolff RF, Bala MM, Westwood M, et al., $5 \%$ lidocaine-medicated plaster vs other relevant interventions and placebo for post-herpetic neuralgia (PHN): a systemic review, Acta Neurol Scand, 2011;123:295-309.

44. Katz NP, Gammaitoni AR, Davis MW, Dworkin RH, Lidoderm Patch Study Group, Lidocaine patch $5 \%$ reduces pain intensity and interference with quality of life in patients with postherpetic neuralgia: an effectiveness trial, Pain Med, 2002;3:324-32.

45. Kim JY, Lim WJ, Lee SJ, et al., Efficacy of piroxicam patch compared to lidocaine patch for the treatment of postherpetic neuralgia, Ann Dermatol, 2011;23:162-9.

46. Rehm S, Binder A, Baron R, Post-herpetic neuralgia: $5 \%$ lidocaine medicated plaster, pregabalin, or a combination of both? A randomized, open, clinical effectiveness study, Curr Med Res Opin, 2010;26:1607-19.

47. Wasner G, Kleinert A, Binder A, et al., Postherpetic neuralgia: topical lidocaine is effective in nociceptor-deprived skin J Neurol, 2005;252:677-86.

48. Gilron I, Bailey JM, Tu D, et al., Morphine, gabapentin, or their combination for neuropathic pain, N Engl I Med, 2005;352:1324-34.

49. Eisenberg E, MCNicol ED, Carr DB, Efficacy and safety in the treatment of neuropathic pain of nonmalignant origin: systematic review and meta-analysis of randomized controlled trials, JAMA, 2005;293:3043-52.

50. Sang CN, Booker S, Gilron I, et al., Dextromethorphan and memantine in painful diabetic neuropathy and postherpetic neuralgia: efficacy and dose-response trials, Anesthesiology, 2002;96:1053-61.

51. Derry S, Lloyd R, Moore RA, McQuay HJ, Topical capsaicin for chronic neuropathic pain in adults, Cochrane Database Syst Rev, 2009;(4):CD007393

52. Gilron I, Bailey JM, Tu D, et al., Nortriptyline and gabapentin, alone and in combination for neuropathic pain: a double-blind, randomised controlled crossover trial, Lancet, 2009;374:1252-61. 


\section{$\mathbb{A}$}

THE EUROPEAN ASSOCIATION

OF NEUROSURGICAL SOCIETIES

Treating Patients -

Preserving Functions -

Exploring Brain

\section{EANS 2012}

European Association of Neurosurgical Societies

Bratislava, Slovakia

24-27 October 2012

\section{REGISTER NOW}

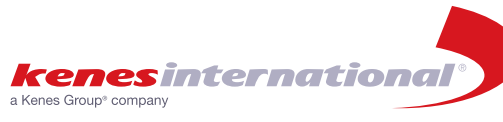

Kenes International, 1-3 Rue de Chantepoulet, PO Box 1726 $\mathrm{CH}-1211$ Geneva 1 Switzerland, Tel:+ 4122908 0488; Fax:+ 41229069140 E-mail: eans@kenes.com 


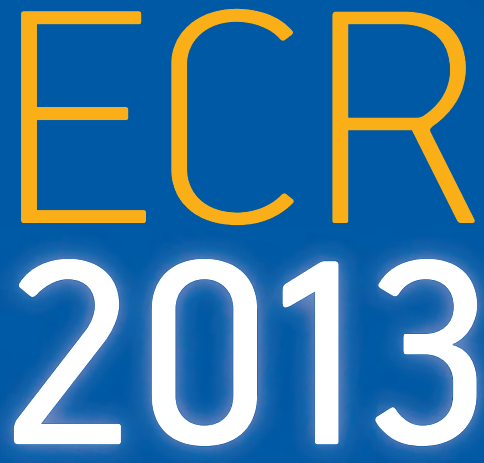

\section{Scientific Highlights:}

»ESR meets Chile, South Africa, Spain »New Horizons Session on MR/PET

»State of the Art Symposium on evaluation of response in haematological malignancy

» Professional Challenges Session on personalised radiology

»Categorical Courses on oncologic imaging and on arteries

» Mini Courses on controversies in breast imaging and on oncologic imaging

» Foundation Course on neuroimaging

» Multidisciplinary Sessions on managing patients with cancer

»More Interactive Sessions

»More Multidisciplinary Sessions

\section{MVESR.org}

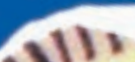
. 


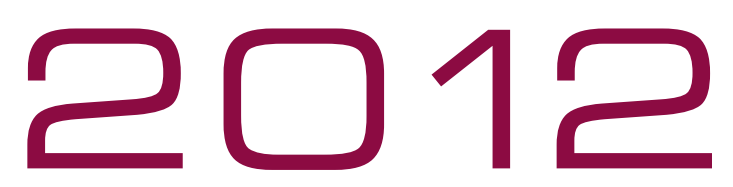

\section{AMERICAN EPILEPSY SOCIETY GgTH ANNUAL MEETING \\ $4^{\text {th }}$ Biennial North American Epilepsy Congress}
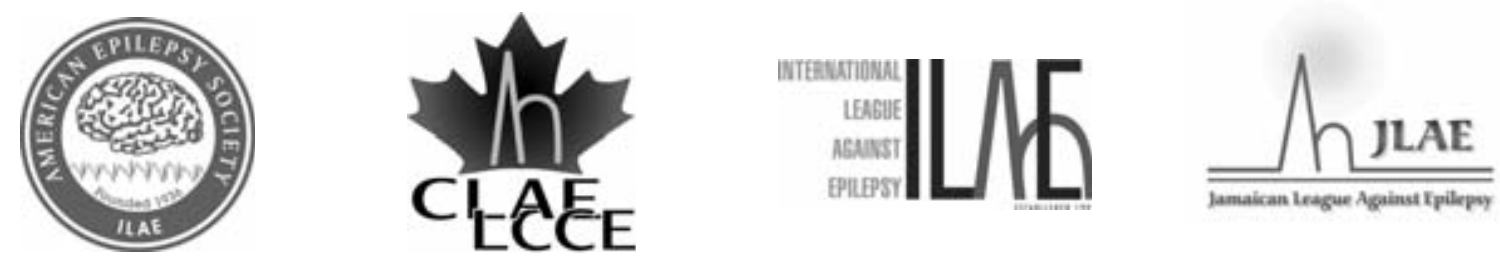

\section{SAN DIEGO, CA}

SAN DIEGO

CONVENTION CENTER

November 30 - December 4

\section{MPORTANT HIEHLIEHTS}

- GME Symposia and Lectures

- Platform Sessions

- Poster Sessions

- Commercial Exhibits

- Special Interest Group Meetings

\section{WWW.AESNET.ONg}

\section{Future Annual Meeting Dates}

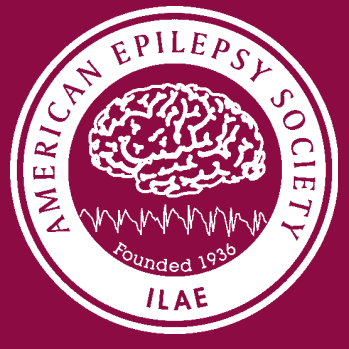

2013

Washington, D.G.

Washington Convention Center

December 6 - 10

2014

Seattle, WA

Washington State Convention and

Trade Center

December 5 - 9
2015

Philadelphia, PA

Pennsylvania Convention Center

December 4 - 8

2016

Houston, TX

George R. Brown Convention Center

December $2-6$ 


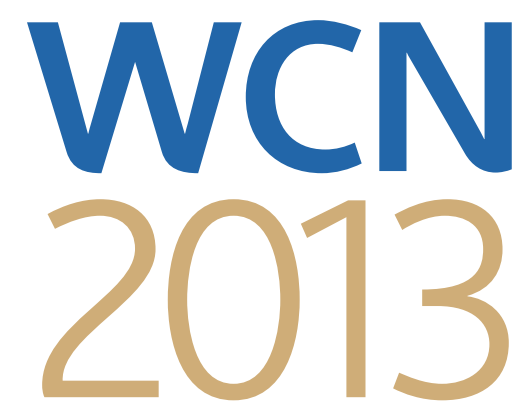

THE XXI WORLD CONGRESS OF NEUROLOGY

\section{SAVE THE DATE}
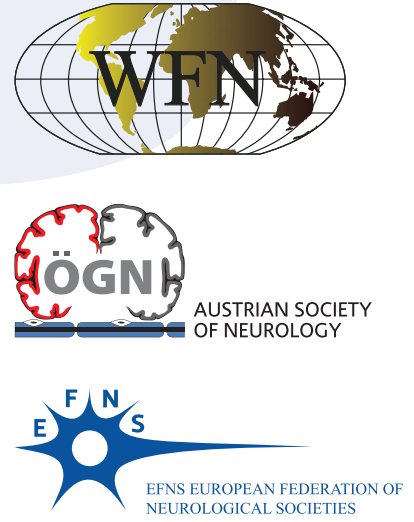

Vienna, Austria, 21-26 September 2013

NEUROLOGY IN THE AGE OF GLOBALISATION

w w w. w c n-neurology.com

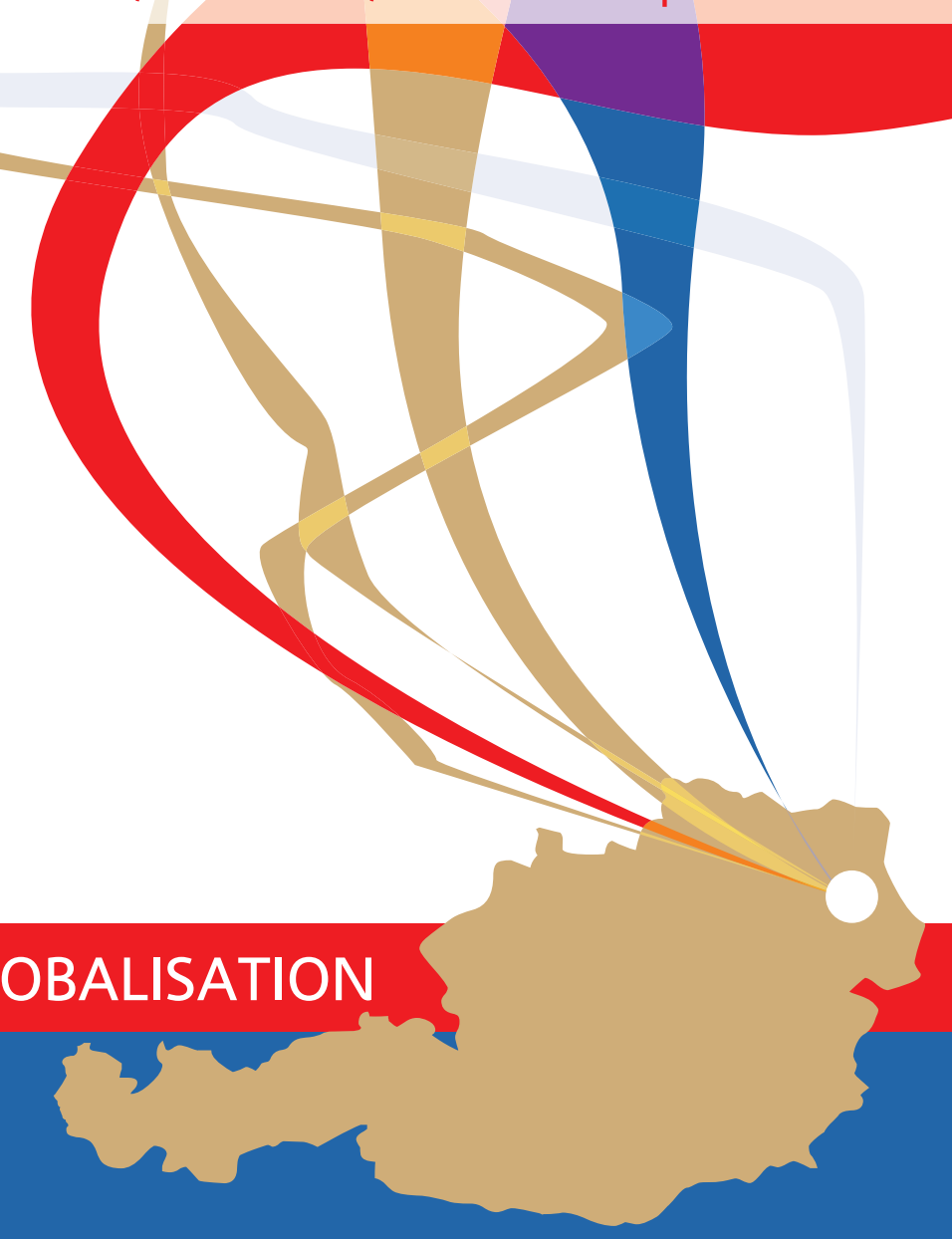




\section{SUPPORTING EXCELLENE IN CLIMICAL PRACTICE}

\section{w w w . toughneurology. com}

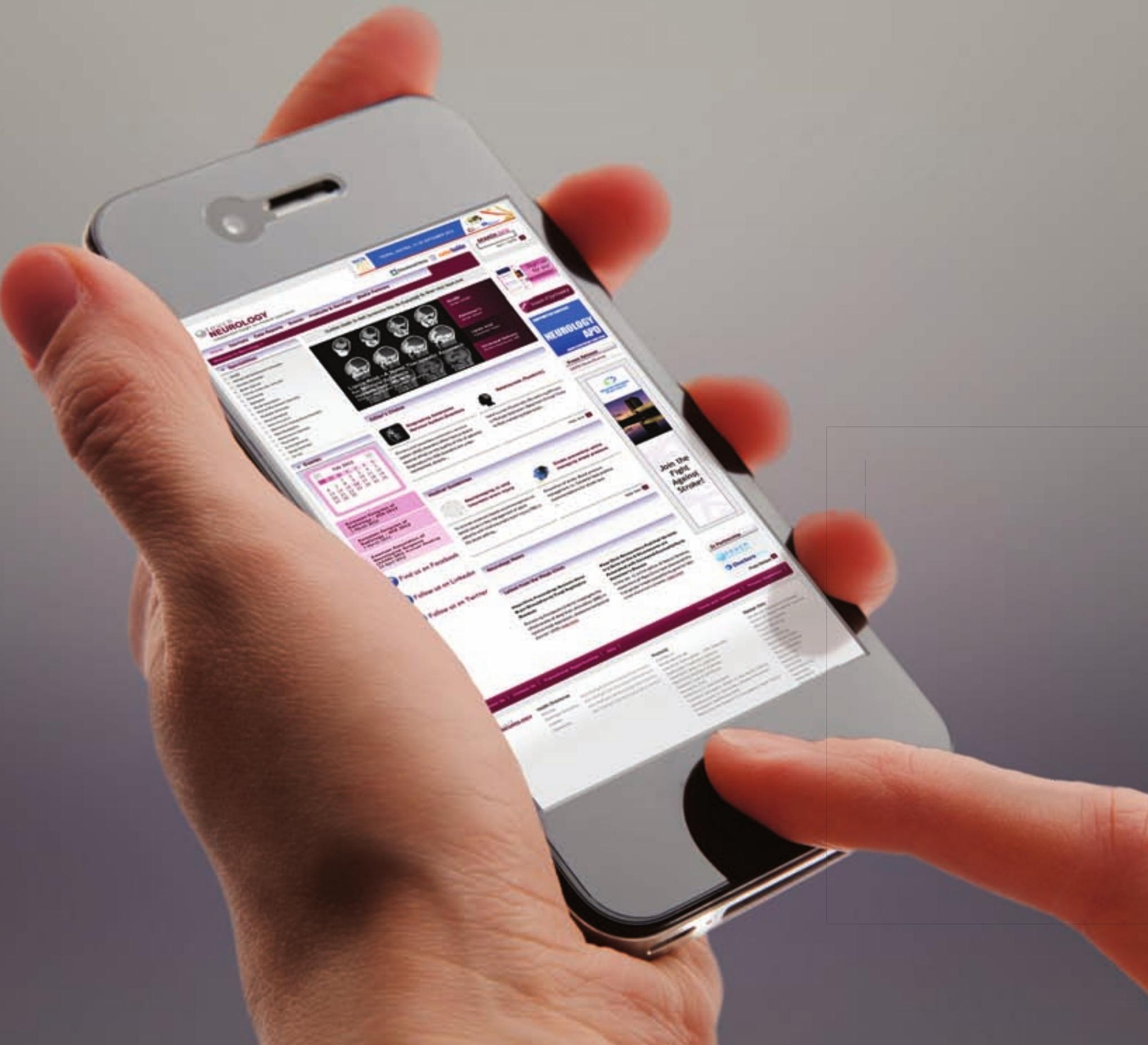

